\title{
The early thermal and magnetic state of the cratered highlands of Mars
}

\author{
Javier Ruiz $^{\mathrm{a}, *}$, Patrick J. McGovern ${ }^{\mathrm{b}}$, Rosa Tejero ${ }^{\mathrm{a}}$ \\ ${ }^{a}$ Departamento de Geodinámica, Facultad de Ciencias Geológicas, Universidad Complutense de Madrid, 28040 Madrid, Spain \\ ${ }^{\mathrm{b}}$ Lunar and Planetary Institute, 3600 Bay Area Boulevard, Houston, TX 77058, USA
}

Received 6 July 2004; received in revised form 22 August 2005; accepted 13 October 2005

Available online 28 November 2005

Editor: R.D. van der Hilst

\begin{abstract}
Surface heat flows are calculated from elastic lithosphere thicknesses for the heavy cratered highlands of Mars, in terms of the fraction of the surface heat flow derived from crustal heat sources. Previous heat flow estimations for Mars used linear thermal gradients, which is equivalent to ignoring the existence of heat sources within the crust. We compute surface heat flows following a methodology that relates effective thickness and curvature of an elastic plate with the strength envelope of the lithosphere, and assuming crustal heat sources homogeneously distributed in a radioactive element-rich layer 20 or $60 \mathrm{~km}$ thick. The obtained results show that the surface heat flow increases with the proportion of heat sources within the crust, and with the decrease of both radioactive element-rich layer thickness and surface temperature. Also, the results permit us to calculate representative temperatures for the crust base, rock strength for the upper mantle, and lower and upper limits to the crustal magnetization depth and intensity, respectively. For Terra Cimmeria, an effective elastic thickness of $12 \mathrm{~km}$ implies between $30 \%$ and $80 \%$ of heat sources located within the crust. In this case the uppermost mantle would be weak at the time of loading, and temperatures in the lower crust cold enough to favor unrelaxed crustal thickness variations and to permit deep Curie depths in the highlands, as suggested by the observational evidence.
\end{abstract}

Keywords: Mars; elastic thickness; heat flow; thermal structure; Curie depth

\section{Introduction}

The heavily cratered highlands of Mars, mainly located in the southern hemisphere, contain the oldest terrain on the planet (Fig. 1 shows a map with the geographical features discussed in this paper). Martian highlands basement dates from the Early Noachian

\footnotetext{
* Corresponding author. Tel.: +34 394913944829; fax: +34 913944631.

E-mail address: jaruiz@geo.ucm.es (J. Ruiz).
}

period (e.g., 1), which ended between 3.8 and 4.1 Gyr ago [2]. The Noachian epoch is the earliest period of the Martian chronology (established by crater counts), ranging from the formation of the planet to between 3.5 and $3.7 \mathrm{Gyr}$ ago (the start of the Hesperian epoch $[2,3]$ ). The existence of long-wavelength crustal thickness variations in the highlands has been inferred from inversions of topography and gravity data [4]. Such variations probably have survived throughout Martian history and therefore require ancient lower crust temperatures cold enough to prevent their relaxation until the present day [4-7]. Some regions of the 


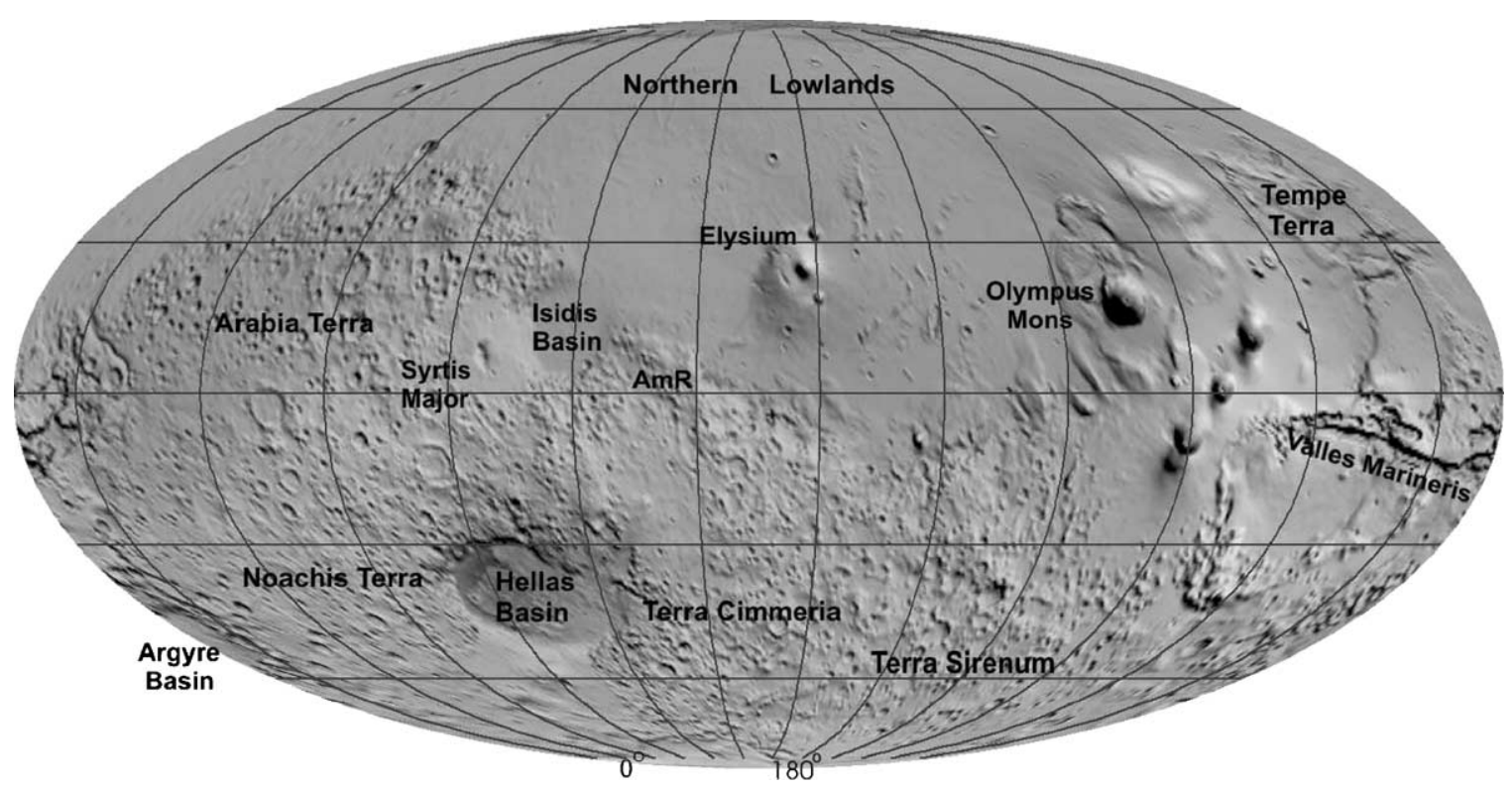

Fig. 1. Map of Mars with the geographical features discussed in this paper and other representative features indicated on MOLA topography [42]. The label AmR indicates the Amenthes Rupes region. The cratered highlands are mainly located in the Southern Hemisphere.

highlands (principally in Terra Cimmeria and Terra Sirenum) display strong (likely remnant) magnetization [8-10]. The thickness of the strongly magnetized material is limited by the depth to the Curie temperature, for the minerals that carry the magnetization, at the time when the magnetization was established. So, the thermal state of the highlands has important implications for the stability of crustal thickness variations against relaxation, and for the thickness of the magnetized crust.

Previous works have estimated surface heat flow for diverse regions of Mars, deduced from the effective elastic thickness of the lithosphere at the time of loading (e.g., [4,11-15]), or from faulting depth [16]. Such heat flow estimates are relevant for the loading and the faulting time, respectively. These studies used linear thermal gradients (equivalent to ignoring the presence of heat sources within the crust), so that the obtained heat flow values are lower limits.

In this paper we take into account the existence of crustal heat sources in the calculation of surface heat flows for Mars. From arguments drawn from Martian surface materials analyzed in Pathfinder soils and rocks, or from orbital observations, it has been proposed that over $50 \%$, or even $75 \%$, of radioactive heat sources in Mars are located in the crust [17]. For comparison, in the Earth, roughly half of the heat flow lost in continental areas originates from crustal heat sources. We used our results to calculate representative temperatures for the base of the crust (of critical importance to considerations of stability against relaxation of the highlands crust thickness variations), to calculate rock strength in the uppermost mantle (in order to analyze the possible bounds on heat sources located in the crust), and to obtain lower and upper limits to the crustal magnetization depth and intensity, respectively.

\section{Crustal temperature profiles and estimation of surface heat flows}

The temperature-depth profile in a planetary crust is a function of the amount and distribution of crustal heat sources. Apart from general considerations (e.g., [17]), the distribution (and intensity) of heat sources in the Mars' crust is poorly constrained. For this reason, here we assume crustal heat sources homogeneously distributed in a radioactive element-rich layer (not necessarily equivalent to the whole crust) 20 or $60 \mathrm{~km}$ thick. The higher value corresponds to a typical value for mean thickness of the highland crust deduced from topography and gravity $[18,19]$. The lower value is taken to make the lower limit agree with the estimations of 20-30 km for the thickness of an enriched crust deduced from the geochemistry of Martian meteorites [20]. A nearly homogeneous distribution of radioactive heat sources is in accordance with the suggestion that vertical differentiation in the Martian crust is less important than in the terrestrial continental crust [17].

If $f$ is the fraction of the surface heat flow derived from crustal heat sources, the temperature at 
depth $z\left(T_{z}\right)$ within the radioactive element-rich layer is given by

$$
T_{z}=T_{\mathrm{s}}+\frac{F z}{k}\left(1-\frac{f z}{2 b}\right)
$$

where $T_{\mathrm{s}}$ is the surface temperature, $F$ is the surface heat flow, $k$ is the thermal conductivity of the crust, and $b$ is the thickness of the radioactive element-rich layer; the factor $f$ can be formally defined as $A b / F$, where in turn $A$ is the volumetric heat production rate. On Earth, radiogenic sources are sparse beneath the upper radioactive element-rich layer (e.g., 21), and so, for the $b=20 \mathrm{~km}$ case we use a linear thermal profile between 20 and $60 \mathrm{~km}$ depth, calculated according to

$T_{z}=T_{\mathrm{b}}+\frac{F(1-f)(z-b)}{k}$,

where $T_{\mathrm{b}}$ is the temperature at the base of the radioactive element-rich layer, given by Eq. (2). The thermal conductivity is taken as $2.5 \mathrm{~W} \mathrm{~m}^{-1}$ $\mathrm{K}^{-1}$, a value frequently taken as representative of the terrestrial crust and it is also the mean value for diabase [22], a rock type commonly taken to represent the mechanical behavior of the Martian crust. In this work temperature profiles will be calculated for two different values of the surface temperature: $220 \mathrm{~K}$ (the present-day mean surface temperature [23]) and $273 \mathrm{~K}$ (perhaps appropriate for a warm and wet early Mars; e.g., [24]).

We compute surface heat flows following the methodology described in McNutt [25], which relates effective thickness of an elastic plate $\left(T_{\mathrm{e}}\right)$ to the mechanical thickness $T_{\mathrm{m}}$ of an elastic-plastic plate via a lithospheric strength envelope. The bending moment of the two types of plate must match. The bending moment of the elastic plate is

$M=\frac{E K T_{\mathrm{e}}^{3}}{12\left(1-v^{2}\right)}$,

where $E$ is the Young's modulus, $K$ is the topography curvature, and $v$ is the Poisson's coefficient. The bending moment of the lithosphere is given by

$$
M=\int_{0}^{T_{\mathrm{m}}} \sigma(z)\left(z-z_{\mathrm{n}}\right) \mathrm{d} z
$$

where $T_{\mathrm{m}}$ is the mechanical thickness of the lithosphere, $\sigma(z)$ is the least, at depth $z$, of the brittle strength, the ductile strength, or the fiber stress, and $z_{\mathrm{n}}$ is the depth to the neutral stress plane. Additionally, the condition of zero net axial force is imposed,

$$
\int_{0}^{T_{\mathrm{m}}} \sigma(z) \mathrm{d} z=0 .
$$

We calculated the brittle strength by the low-pressure Byerlee's rule (as in Brace and Kohlstedt [26]) for zero pore pressure and a crustal density of $2900 \mathrm{~kg} \mathrm{~m}^{-3}$. (If substantial pore pressure was present in the Martian lithosphere in the early Noachian the brittle strengths would have been lower, which in turn implies lower heat flows to obtain strength envelopes with the required bending moment.) The temperature-dependent ductile strength is calculated for the flow law of diabase [27] in terms of temperatures given by Eq. (1) or Eq. (2), and is then linearized following the method in McAdoo [28]. The fiber stress is calculated from curvature according to, for example, Turcotte and Schubert [21], using lithospheric constants as in McGovern et al. [13]. The surface heat flow is calculated for each set of values of elastic thickness, plate curvature, $T_{\mathrm{s}}, f$, and $b$, by simultaneously solving Eqs. (1) and (2), and in the $b=20 \mathrm{~km}$ case, Eqs. (4) and (5).

Estimates of elastic thickness from gravity/topography admittance and correlation spectra for several regions on the southern highlands give values lower than $12-16 \mathrm{~km}[13,14]$, although in general the best-fit values were for $T_{\mathrm{e}}=0$ (Airy compensation). These results are similar to the $12-15 \mathrm{~km}$ obtained for the elastic thickness in the regions located southward the $-20^{\circ}$ latitude considered as a whole [29], and to the 10$15 \mathrm{~km}$ obtained for Syrtis Major [15]. Here we use elastic thicknesses for Cimmeria, Noachis and Arabia Terrae from McGovern et al. [14] in order to calculate lower limits to the surface heat flow, for the loading time, at these locations. We calculate ductile strength using a slow strain rate of $10^{-19} \mathrm{~s}^{-1}$. This strain rate is consistent with estimates of $\sim 10^{-19} \mathrm{~s}^{-1}$ for the Tempe Terra extensional province [30], and $10^{-17}-10^{-19} \mathrm{~s}^{-1}$ for the Amenthes Rupes thrust fault population [31], both geological setting being more tectonized than Terra Cimmeria (the main focus in this work) and Noachis terra. Because the elastic thickness estimates used here are upper limits, the calculated surface heat flows are lower limits. 


\section{Results}

\subsection{Surface and mantle heat flow, and crustal heating rate}

Surface heat flows calculated for Terra Cimmeria are shown in Fig. 2a. Surface heat flow increases with the proportion of heat sources $(f)$ within the crust. Also, heat flows are higher for the case with $20-\mathrm{km}$-thick radioactive element-rich layer, and for the case with lower surface temperature. Results for Noachis Terra and Northeastern Arabia Terra are similar (for Northeastern Arabia Terra the upper limit for the thickness of the radioactive element-rich layer was taken as $50 \mathrm{~km}$, in accordance with crustal thicknesses obtained for this region by Neumann et al. [19]). Table 1 shows results for the three regions in the $T_{\mathrm{s}}=220 \mathrm{~K}$ nominal case and $f=0$ (no crustal heat sources), $f=0.5$ (half of heat sources located in the radioactive element-rich layer), and $f=1$ (all heat sources located in the radioactive element-rich layer).

Figs. $2 \mathrm{~b}$ and 3 show, respectively, the mantle heat flow and the crustal radioactive heat production rate at Terra Cimmeria. Mantle heat flow decreases with increasing $f$ (obviously it is zero for $f=1$ ), whereas the opposite is true for the crustal heat production. Both mantle heat flow and crustal heat production are higher for low values of $b$ and/or $T_{\mathrm{s}}$.

\subsection{Crustal geotherms and temperature at the base of the crust}

Our heat flow results can be used to calculate temperatures within the highlands crust. Fig. 4 shows crustal geotherms for $T_{\mathrm{s}}=273 \mathrm{~K}$ and $f=0$ (linear thermal gradient), 0.5 and 1 ; results for $T_{\mathrm{s}}=220 \mathrm{~K}$ are similar. It can be seen that geotherms are relatively similar (except in the case with $b=20 \mathrm{~km}$ and $f=1$ ) in the upper part of the crust, but they are clearly divergent, due to the specific values for $b$ and $f$, in the lower part of the crust. For the case with $b=20 \mathrm{~km}$ and $f=1$ the temperature is constant below the radioactive element-rich layer (which is as unrealistic as a strictly linear thermal gradient). The zero strength level for the linearized ductile portion of the strength envelope is reached at a depth of $\sim 20-21 \mathrm{~km}$ in all the cases. Therefore, the divergence of geotherms in the lower crust is not relevant for surface heat flow calculations, but it is very important for considerations of the thermal state of the lower crust and mantle.

In order to obtain temperatures representatives of the crust base, we estimate, from heat flow values in Fig. 2, (a)

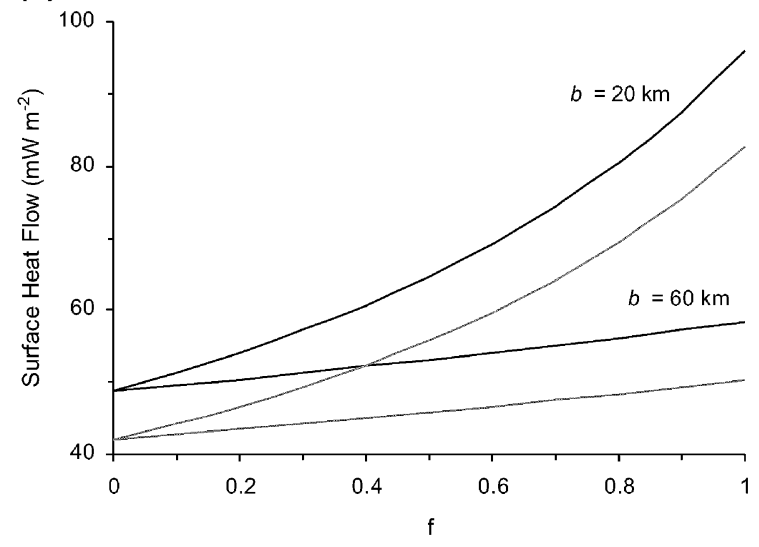

(b)

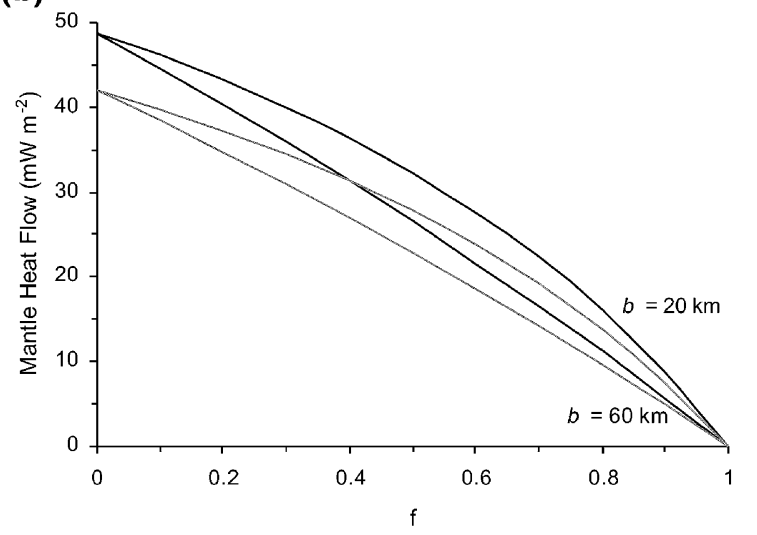

Fig. 2. Lower limits to the (a) surface and (b) mantle heat flow estimated for Terra Cimmeria as functions of the fraction of surface heat flow originated from crustal heat sources, $f$. Solid and gray curves indicate surface temperatures of $220 \mathrm{~K}$ and $273 \mathrm{~K}$, respectively.

the temperature at $60 \mathrm{~km}$ depth in terms of $f$, for both $b=20$ and $60 \mathrm{~km}$, and the results are shown in Fig. 5 (see also Fig. 4). It is clear that an increase in $f$ causes a drastic decrease in lowermost crust temperatures, which is more evident for the $b=20$ case. These low temperatures appear to be cold enough (when compared with theoretical models [5-7]) to permit long-wavelength highlands crustal thickness variations to be stable against relaxation during the Noachian. Subsequent post-Noachian cooling (e.g., $[13,14]$ ) will further stabilize the highlands crust.

\subsection{Rock strength of the uppermost mantle}

A cooler lower crust also implies a cooler (and stronger) upper mantle. A strong upper mantle is inconsistent with a thin effective elastic thickness for the lithosphere of the highlands. Thus, rock strength at the top of the mantle can be used to analyze the range of possible $f$ (and surface heat flow) values. Indeed, the 
Table 1

Summary of surface heat flows $(F)$ estimated from elastic thicknesses $\left(T_{\mathrm{e}}\right)$ and maximum curvature of the elastic plate $(K)$, for $T_{\mathrm{s}}=220 \mathrm{~K}$

\begin{tabular}{|c|c|c|c|c|c|}
\hline \multirow[t]{2}{*}{ Region } & \multirow[t]{2}{*}{$\begin{array}{l}T_{\mathrm{e}} \\
(\mathrm{km})^{\mathrm{a}}\end{array}$} & \multirow[t]{2}{*}{$\begin{array}{l}K \\
\left(10^{-8} \mathrm{~m}^{-1}\right)^{\mathrm{b}}\end{array}$} & \multicolumn{3}{|c|}{$\begin{array}{l}F \\
\left(\mathrm{~mW} \mathrm{~m}^{2}\right)\end{array}$} \\
\hline & & & $f=0$ & $f=0.5$ & $f=1$ \\
\hline Northeastern Terra Cimmeria & $<12$ & $>42$ & $>49$ & $>53-65$ & $>58-96$ \\
\hline Noachis Terra & $<12$ & $>31$ & $>53$ & $>57-68$ & $>62-97$ \\
\hline Northeastern Arabia Terra & $<16$ & $>24$ & $>42$ & $>47-58$ & $>54-91$ \\
\hline
\end{tabular}

The thickness of the radioactive element-rich layer $(b)$ is $20-60 \mathrm{~km}$ for northeastern Terra Cimmeria and Noachis Terra, and 20-50 km for northeastern Arabia Terra.

${ }^{\mathrm{a}}$ McGovern et al. [14].

${ }^{\mathrm{b}}$ Concave downward in every case.

base of the Earth's mechanical lithosphere can be defined as the depth for which the strength reaches some low value, usually taken as $50 \mathrm{MPa}$ [25] or $10 \mathrm{MPa}$ [32]. Since brittle strengths are lower for Mars than for Earth, a lower strength value should be more appropriate for Mars. So, we chose $10 \mathrm{MPa}$ as the strength level defining the base of the Martian mechanical lithosphere, and we consider $50 \mathrm{MPa}$ as more applicable to a higher-gravity planet like Earth. In this case, the threshold strengths for the two planets have similar proportions to the maximum stresses found in the lithosphere.

Accordingly, strength values in the uppermost mantle higher than $10 \mathrm{MPa}$ are taken as inconsistent with a weak mantle and a thin effective elastic thickness. Fig. 6 shows the strength for the top of the mantle, calculated for temperatures at crust-mantle boundary in Fig. 5 using the flow laws of dunite [33]: $f$ values up to $0.53-0.79$ (0.53-0.62 and $0.66-0.79$ for $b=20$ and $60 \mathrm{~km}$, respectively) are consistent with a weak upper mantle, and so with a thin effective elastic thickness. As the depth to the base of the radiogenic layer $b$ decreases, the allowable range of $f$ values also decreases.

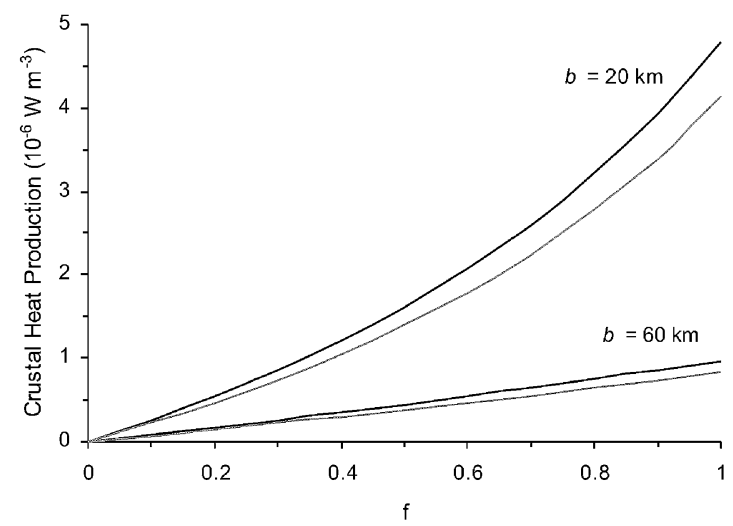

Fig. 3. Crustal radioactive heating rates as functions of $f$, calculated for results in Fig. 2a. Solid and gray curves indicate surface temperatures of $220 \mathrm{~K}$ and $273 \mathrm{~K}$, respectively.
Although we prefer the value of $10 \mathrm{MPa}$ to define the base of the Martian mechanical lithosphere, it is worth to mention that a higher strength level would imply a wider $f$ range: up to $0.66-0.95$ for $50 \mathrm{MPa}$, or up to $0.63-0.91$ for the intermediate value of $30 \mathrm{MPa}$.

\subsection{Depth of magnetization in the southern highlands}

The strong magnetic anomalies observed by the Mars Global Surveyor magnetometer on the southern highlands, and especially on Terra Cimmeria and Terra Sirenum [8-10], have been attributed to crustal remnant magnetization, which was acquired previous to the impact events creating the essentially non-magnetized Hellas, Argyre and Isidis basins [8,34], which are superimposed on the highlands. The base of the strongly magnetized layer may correspond to the depth to the Curie temperature for the main mineral carrying magnetization, when the magnetization was acquired, but it is also possible that it reflects chemical composition or state changes [10]. Subsequent lithosphere cooling can produce weak magnetization under the primarily

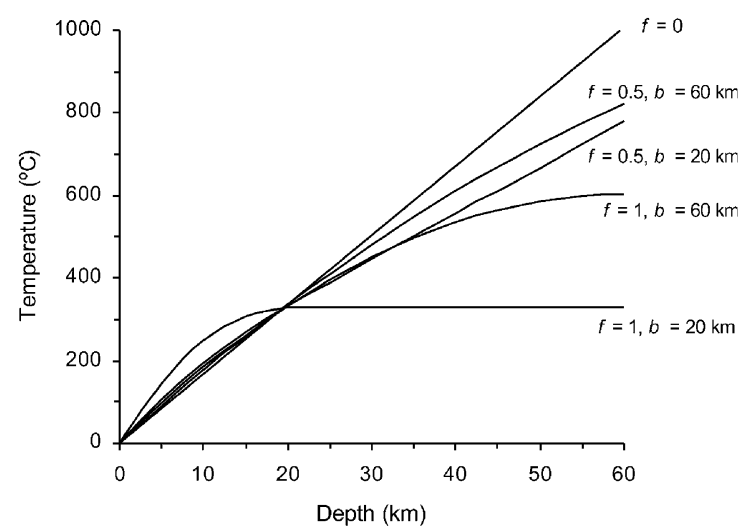

Fig. 4. Crustal geotherms calculated for $T_{\mathrm{S}}=273 \mathrm{~K}$ using heat flow results in Fig. 2. Labels indicate $f$ values and radioactive element-rich layer thicknesses (the $f=0$ case corresponds to a linear thermal gradient for both cases of crustal thickness). 


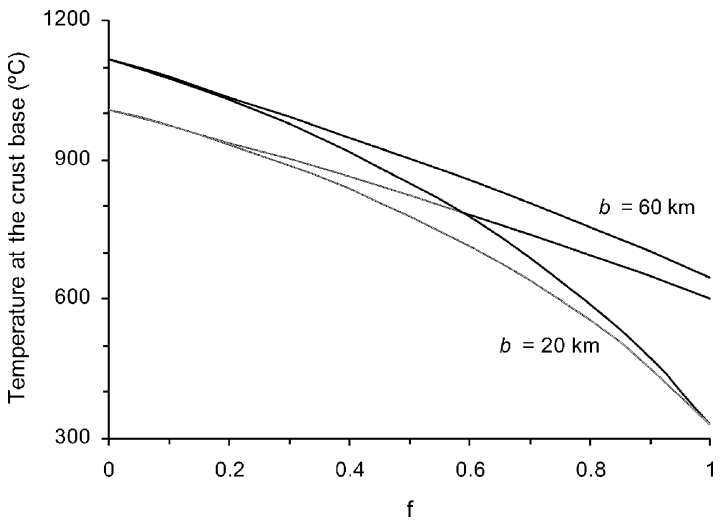

Fig. 5. Temperatures at the base of the crust as functions of $f$, calculated for heat flows in Fig. 2. Black and gray curves indicate surface temperatures of $220 \mathrm{~K}$ and $273 \mathrm{~K}$, respectively.

magnetized crust in absence of core magnetic field, although it is unlikely that secondary magnetization contributes significantly to the observed magnetic anomalies [35]. In any case, when the crust was first magnetized the temperature at the base of the strongly magnetized layer should be equal to or less than the appropriate Curie temperature, otherwise the crustal rocks could not retain magnetization.

Given similarly ancient inferred ages of and topography formation and strong crustal magnetization for the cratered highlands, both the results obtained in Section 3.1 and Eqs. (1) and (2) can be used to calculate the depth to the Curie temperature at the time when magnetization was acquired. Depths obtained in this way represent the maximum thickness of magnetized crust, because crust shallower than Curie depth might not be totally magnetized. The main magnetization

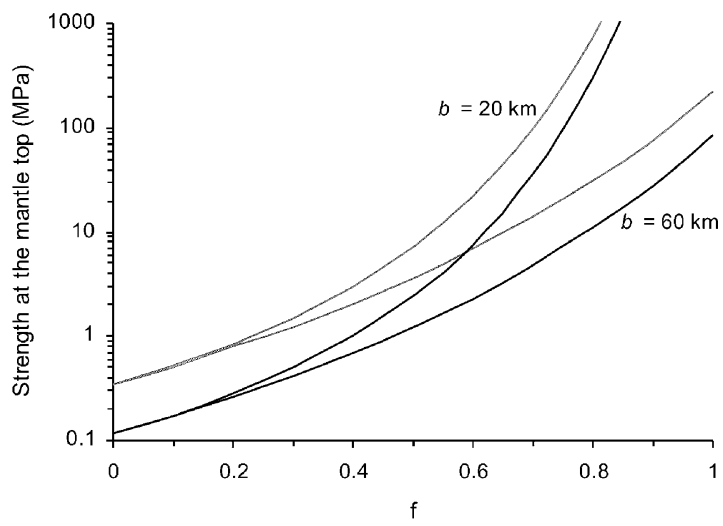

Fig. 6. Strength at the top of the mantle, calculated for crustal base temperatures shown in Fig. 5 as a function of $f$. Black and gray curves indicate surface temperatures of $220 \mathrm{~K}$ and $273 \mathrm{~K}$, respectively. carrier could be pyrrhotite, magnetite, or hematite [9,10,36-38]. Here we performed the calculations for these three minerals, using Curie temperatures of $325{ }^{\circ} \mathrm{C}, 580{ }^{\circ} \mathrm{C}$ and $670{ }^{\circ} \mathrm{C}$ respectively, and we use the heat flows shown in Fig. $2 \mathrm{a}$.

Results are shown in Fig. 7a (for $b=60 \mathrm{~km}$ ) and $7 \mathrm{~b}$ (for $b=20 \mathrm{~km}$ ). The Curie depth for pyrrhotite is nearly constant, and it is lower than $20 \mathrm{~km}$ in all the cases. Otherwise, Curie depth for both magnetite and hematite increases with the proportion of crustal heat sources (related with lower crustal temperatures) and with surface temperatures (since increasing surface temperature decreases heat flow values). The minimum Curie depths for magnetite and hematite correspond to the $f=0$ case, and they are $32-35$ and $37-40 \mathrm{~km}$ respectively. Increasing $f$ increases Curie depths. For magnetite and $b=60 \mathrm{~km}$, the maximum Curie depth is
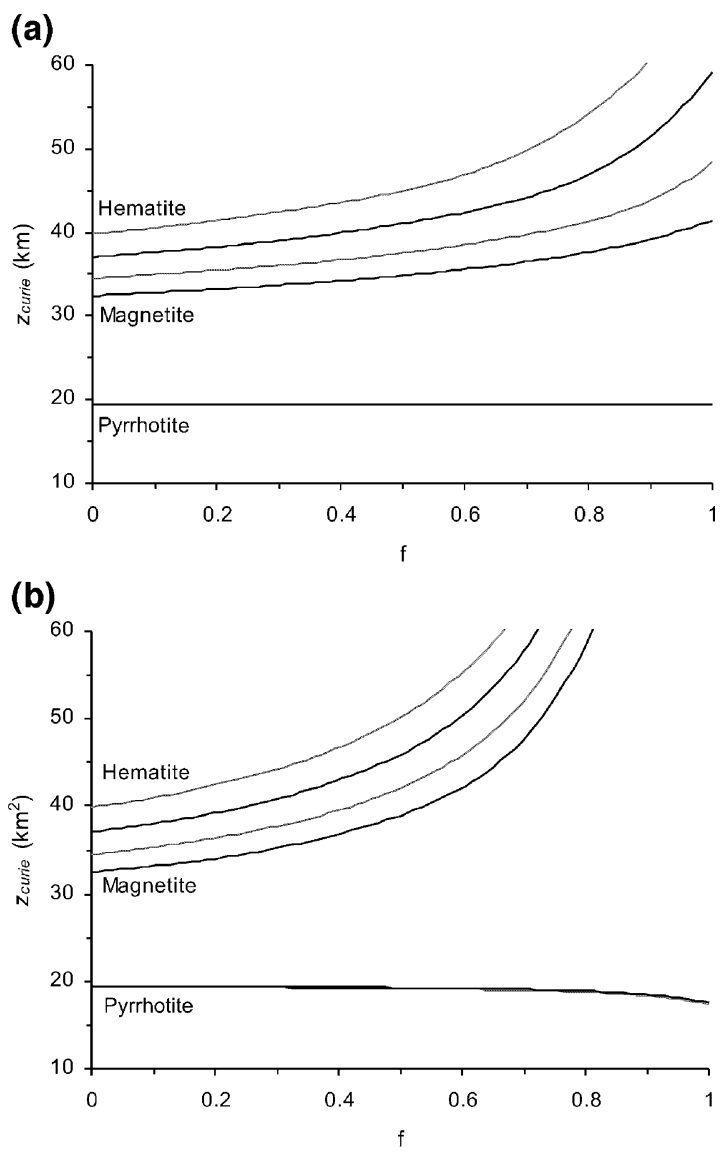

Fig. 7. Curie depths for pyrrhotite, magnetite and hematite as functions of $f$, calculated for heat flows in Fig. 2. Black and gray curves indicate surface temperatures of $220 \mathrm{~K}$ and $273 \mathrm{~K}$, respectively (for the pyrrhotite case the both curves are superimposed). (a) $b=60 \mathrm{~km}$, (b) $b=20 \mathrm{~km}$. 
$41-48 \mathrm{~km}$ for $f=1$. For magnetite and $b=20 \mathrm{~km}$, and for hematite, Curie depths can be deeper than crust base provided an $f$ value sufficiently higher.

\subsection{Intensity of magnetization in the southern highlands crust}

The intensity of magnetization in Terra Cimmeria and Terra Sirenum is an order of magnitude higher than those typical on the Earth [9]. Connerney et al. [9] have modeled the magnetization for a 30-km-thick magnetized layer, and they have obtained an intensity of $20 \mathrm{~A}$ $\mathrm{m}^{-1}$, which is comparable to that in fresh ocean-floor basalts. The intensity of magnetization is inversely proportional to the magnetized thickness. So, Curie depths in Fig. 7a and $b$ can be used to recalculate the minimum rock magnetization intensity in terms of the maximum thickness of the magnetized layer. The intensity in the magnetized rocks can be higher than the calculated values, since the crust above Curie depth is not necessarily magnetized through its entire thickness.

For pyrrothite, magnetization is higher than $30 \mathrm{~A}$ $\mathrm{m}^{-1}$ in all the cases. The results for magnetite and hematite are summarized in Fig. 8. In this figure only end-member scenarios $\left(b=60 \mathrm{~km}, T_{\mathrm{s}}=220 \mathrm{~K}\right.$, and $\left.b=20 \mathrm{~km}, T_{\mathrm{s}}=273 \mathrm{~K}\right)$ are shown. Hematite exhibits the lowest minimum magnetization, due to its higher Curie temperature (and hence Curie depth). Increasing the fraction of crustal heat sources $f$ decreases the required magnetization, due to cooler temperatures (and hence deeper Curie depths) in the lower crust (Figs. 5 and 7). In any case, crustal magnetization is clearly stronger in the highlands crust than that in the majority of terrestrial rocks [38].

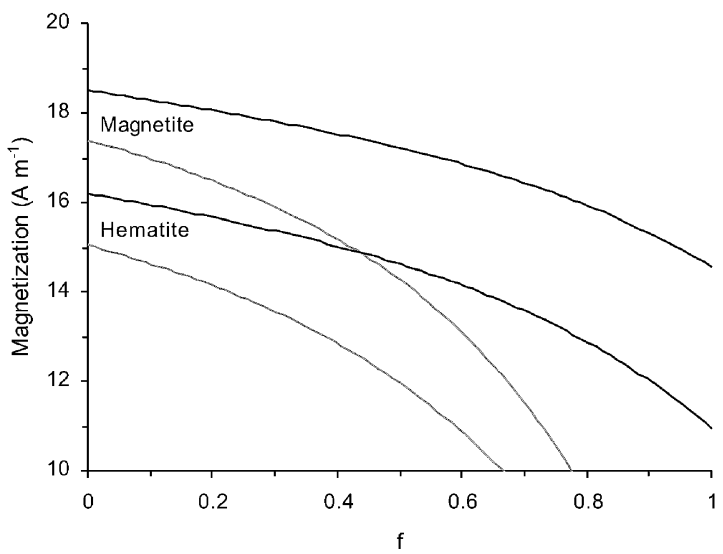

Fig. 8. Minimum magnetization intensity for magnetite and hematite as functions of $f$. Black curves are for $b=60 \mathrm{~km}$ and $T_{\mathrm{s}}=220 \mathrm{~K}$; gray curves are for $b=20 \mathrm{~km}$ and $T_{\mathrm{S}}=273 \mathrm{~K}$.

\section{Discussion}

The heat flow calculations for the $f=0$ case are widely consistent with those in previous work. Our results are very similar to those in McGovern et al. [14], and small differences are due to the slightly different procedure in this work. From faulting depth of Amenthes Rupes thrust fault Schultz and Watters [16] proposed a heat flow of $\sim 54-70 \mathrm{~mW} \mathrm{~m}^{-2}$ for the time when this feature was formed (Late Noachian to Early Hesperian periods, which is equivalent to a maximum possible age range between 3.2 and $3.9 \mathrm{Gyr}$ [2]). These authors used a thermal conductivity of $3.2 \mathrm{~W} \mathrm{~m} \mathrm{~m}^{-1} \mathrm{~K}^{-1}$; re-escaling their results for the $k$ value used in this work (more appropriate for basaltic rocks) the heat flow would be $\sim 42-55 \mathrm{~mW} \mathrm{~m}^{-2}$, similar to the values for $f=0$ obtained here for the highland at the Noachian. From an elastic thickness of $10-15 \mathrm{~km}$ for Syrtis Major, it has been proposed [15] a heat flow of $70-170 \mathrm{~mW} \mathrm{~m}^{-2}$ (for a strain rate range of $10^{-16}-10^{-19} \mathrm{~s}^{-1}$; for $10^{-19} \mathrm{~s}^{-1}$ the heat flow range would be $70-105 \mathrm{~mW} \mathrm{~m}^{-2}$ ) at the Noachian time, by assuming that due to low curvatures in this region elastic and mechanical thicknesses are roughly equivalent. However, because of low Martian gravity, curvatures for which the elastic thickness approach the mechanical thickness are much lesser than for Earth, and for that reason the heat flow proposed for Syrtis Major should be considered as an upper limit.

The inclusion of crustal heat sources in the calculations expands the range of possible heat flow, but it also permits a wider vision of the heat flow problem and related questions. The effect of surface temperature is minor compared to the effects of the presence and distribution of crustal heat sources. As mentioned in Section 3.3, $f$ can be constrained by the condition of a weak uppermost mantle implied by thin effective elastic thickness for the highlands in the Noachian. A further constraint can be imposed from geochemical arguments. Taking crustal abundances of heat producing isotopes as in McLennan [17], a radiogenic heat production rate of $0.8 \mu \mathrm{W} \mathrm{m} \mathrm{m}^{-3}$ at $4 \mathrm{Gyr}$, the nominal age of the cratered highlands, is obtained. By comparing this value with those shown in Fig. 3, values of $f \approx 0.3$ for $b=20 \mathrm{~km}$, and $f \approx 0.85-1$ for $b=60 \mathrm{~km}$ are obtained.

So, taking both constraints into account simultaneously and assuming an effective elastic thickness (at the Noachian time) of $12 \mathrm{~km}$ for Terra Cimmeria, the $f$ value should be between 0.3 and 0.8 . From these values and the results shown in Figs. $2 \mathrm{a}, \mathrm{b}$ and $7 \mathrm{a}, \mathrm{b}$, surface and mantle heat flows of $48-57$ and $10-40 \mathrm{~mW}$ 
$\mathrm{m}^{-2}$, respectively, and Curie depths for magnetite and hematite of $35-41$ and $41-54 \mathrm{~km}$, respectively, are obtained. Analysis of highlands demagnetization by impact cratering suggests that magnetization extends to greater than $\sim 30-40 \mathrm{~km}$ depth [39]. Also, the study of the Mars' magnetic spectrum [40] suggests magnetic sources up to $\sim 50 \mathrm{~km}$ deep. Moreover, it has been suggested [41] that the absence of a magnetic signature associated with the Martian topographic dichotomy boundary indicates that the magnetic sources are mostly placed in the lower part of the crust. These results are inconsistent with Curie depth obtained here for pyrrhotite (if this mineral is taken as the main magnetization carrier), but they widely consistent with our results for magnetite and (especially) hematite.

\section{Conclusion}

Our results show the importance of taking into account the presence of crustal heat sources in calculations of surface heat flows and crustal temperature profiles. Increasing the fraction $f$ of crustal heat sources increases surface heat flow while decreasing lower crustal temperatures. As a consequence, lower crustal isotherms are deeper, and the crust as a whole is colder. Thus, the presence of between $30 \%$ and $80 \%$ of heat sources located within the crust of Mars is consistent with geochemical analysis and allow thin elastic thicknesses deduced for the heavily cratered highland and a weak mantle to be reconciled with both unrelaxed crustal thickness variations and magnetic sources probably placed deep in the lower crust, two lines of evidence suggesting relatively cold temperatures in the early lower crust.

\section{Acknowledgements}

J.R. and R.T. were supported by Spanish Ministerio de Ciencia y Tecnología project BTE200303902, and by a grant of the Spanish Secretaría de Estado de Educación y Universidades to J.R. P.J.M. was supported by NASA Cooperative Agreement Grant NCC5-679 to the Lunar and Planetary Institute. The authors thank James Head and Robert van der Hilst for their reviews, and David Gómez-Ortiz and Josep María Trigo for their help. LPI Contribution number 1256.

\section{References}

[1] H.V. Frey, Large-diameter visible and buried impact basins on Mars: implications for age of the highlands and (buried) low- lands and turn-off of the global magnetic field, Lunar Planet. Sci. 34 (2003) 1838 (CD-ROM).

[2] W.K. Hartmann, Martian cratering 8: isochron refinement and the chronology of Mars, Icarus 174 (2005) 294-320.

[3] W.K. Hartmann, G. Neukum, Cratering chronology and the evolution of Mars, Space Sci. Rev. 96 (2001) 165-194.

[4] M.T. Zuber, S.C. Solomon, R.J. Phillips, D.E. Smith, G.L. Tayler, O. Aharonson, G. Balmino, W.B. Banerdt, J.W. Head, C.L. Johnson, F.G. Lemoine, P.J. McGovern, G.A. Newmann, D.D. Rowlands, S. Zhong, Internal structure and early thermal evolution of Mars from Mars Global Surveyor, Science 287 (2000) $1788-1793$.

[5] F. Nimmo, D.J. Stevenson, Estimates of Martian crustal thickness from viscous relaxation of topography, J. Geophys. Res. 106 (2001) 5085-5098.

[6] E.M. Parmentier, M.T. Zuber, Relaxation of crustal thickness variations on Mars: implications for thermal evolutions, Lunar Planet. Sci. 32 (2001) 1357 (CD-ROM).

[7] E.M. Parmentier, M.T. Zuber, Preservation of crustal thickness variations on Mars: mantle compositional stratification or hydrothermal crustal cooling?, Lunar Planet. Sci. 33 (2002) 1737, (CD-ROM).

[8] M.H. Acuña, J.E.P. Connerney, N.F. Ness, R.P. Lin, D. Mitchell, C.W. Carlson, J. McFadden, K.A. Anderson, H. Rème, C. Mazelle, D. Vignes, P. Wasilewski, P. Cloutier, Global distribution of crustal magnetization discovered by the Mars Global Surveyor MAG/ER experiment, Science 284 (1999) 790-793.

[9] J.E.P. Connerney, M.H. Acuña, P.J. Wasilewski, N.F. Ness, H. Rème, C. Mazelle, D. Vignes, R.P. Lin, D.L. Mitchell, P.A. Cloutier, Magnetic lineations in the ancient crust of Mars, Science 284 (1999) 794-798.

[10] J.E.P. Connerney, M.H. Acuña, P.J. Wasilewski, G. Kletetschka, N.F. Ness, H. Rème, R.P. Lin, D.L. Mitchell, The global magnetic field of Mars and implications for crustal evolution, Geophys. Res. Lett. 28 (2001) 4015-4018.

[11] S.C. Solomon, J.W. Head, Heterogeneities in the thickness of the elastic lithosphere of Mars: constraints on heat flow and internal dynamics, J. Geophys. Res. 95 (1990) 11,073-11,083.

[12] S. Anderson, R.E. Grimm, Rift processes at the Valles Marineris, Mars: constraints from gravity on necking and rate-depending strength evolution, J. Geophys. Res. 103 (1998) 11,113-11,124.

[13] P.J. McGovern, S.C. Solomon, D.E. Smith, M.T. Zuber, M. Simons, M.A. Wieczorek, R.J. Phillips, G.A. Neumann, O. Aharonson, J.W. Head, Localized gravity/topography admittance and correlation spectra on Mars: implications for regional and global evolution, J. Geophys. Res. 107 (2002) 5136, doi:10.1029/2002JE001854.

[14] P.J. McGovern, S.C. Solomon, D.E. Smith, M.T. Zuber, M. Simons, M.A. Wieczorek, R.J. Phillips, G.A. Neumann, O. Aharonson, J.W. Head, Correction to localized gravity/topography admittance and correlation spectra on Mars: implications for regional and global evolution, J. Geophys. Res. 109 (2004) E07007, doi:10.1029/2004JE002286.

[15] W.S. Kiefer, Gravity evidence for a extinct magma chamber beneath Syrtis Major, Marts: a look at the magmatic plumbing system, Earth Planet. Sci. Lett. 222 (2004) 349-361.

[16] R.A. Schultz, T.R. Watters, Forward mechanical modeling of the Amenthes Rupes thrust fault on Mars, Geophys. Res. Lett. 28 (2001) 4659-4662.

[17] S.M. McLennan, Crustal heat production and the thermal evolution of Mars, Geophys. Res. Lett. 28 (2001) 4019-4022. 
[18] M.A. Wieczorek, M.T. Zuber, Thickness of the Martian crust: improved constraints from geoid-to-topography ratios, J. Geophys. Res. 109 (2004) E01009, doi:10.1029/2003JE002153.

[19] G.A. Neumann, M.T. Zuber, M.A. Wieczorek, P.J. McGovern, F.G. Lemoine, D.E. Smith, The crustal structure of Mars from gravity and topography, J. Geophys. Res. 109 (2004) E08002, doi:10.1029/2004JE002262.

[20] M.D. Norman, The composition and thickness of the crust of Mars estimated from rare earth elements and neodymium-isotopic compositions of Martian meteorites, Meteorit Planet. Sci. 34 (1999) 439-449.

[21] D.L. Turcotte, G. Schubert, Geodynamics, Second edition, Cambridge University Press, Cambridge, 2002, 456 pp.

[22] V.N. Kobranova, Petrophysics, Mir, Moscow, 1989, 375 pp.

[23] H.H. Kieffer, T.Z. Martin, A.R. Peterfreund, B.M. Jakosky, E.D. Miner, F.D. Palluconi, Thermal and albedo mapping of Mars during the Viking primary mission, J. Geophys. Res. 82 (1977) 4249-4291.

[24] F.P. Fanale, S.E. Postawko, J.B. Pollack, M.H. Carr, R.O. Pepin, Mars: epochal climate change and volatile history, in: H.H. Kieffer, B.M. Jakosky, C.W. Snyder, M.S. Matthews (Eds.), Mars, University of Arizona Press, Tucson, 1992, pp. $1135-1179$.

[25] M.K. McNutt, Lithospheric flexure and thermal anomalies, J. Geophys. Res. 89 (1984) 11,180-11,194.

[26] W.F. Brace, D.L. Kohlstedt, Limits on lithospheric strength stress imposed by laboratory experiments, J. Geophys. Res. 85 (1980) 6252-6348.

[27] Y. Caristan, The transitions from high temperature creep to fracture in Marylan diabase, J. Geophys. Res. 87 (1982) $6781-6790$.

[28] D.C. McAdoo, C.F. Martin, S. Poulouse, Seasat observations of flexure: evidence for a strong lithosphere, Tectonophysics 116 (1985) 209-222.

[29] D. McKenzie, D.N. Barnett, D.L. Yuan, The relationship between Martian gravity and topography, Earth Planet. Sci. Lett. 195 (2002) $1-16$.
[30] S.J. Wilkins, R.A. Schultz, R.C. Anderson, J.M. Dohm, N.H. Dawers, Deformation rates from faulting at the Tempe Terra extensional province, Mars, Geophys. Res. Lett. 29 (2002), doi:10.1029/2002GL015391.

[31] R.A. Schultz, Seismotectonics of the Amenthes Rupes thrust fault population, Mars, Geophys. Res. Lett. 30 (2003), doi:10.1029/2002GL016475.

[32] G. Ranalli, Nonlinear flexure and equivalent mechanical thickness of the lithosphere, Tectonophysics 240 (1994) 107-114.

[33] P.N. Chopra, M.S. Paterson, The role of water in the deformation of dunite, J. Geophys. Res. 89 (1984) 7861-7876.

[34] J. Arkani-Hamed, A 50-degree spherical harmonic model of the magnetic field of Mars, J. Geophys. Res. 106 (2001) 23,197-23,208.

[35] J. Arkani-Hamed, Thermoremanent magnetization of the Martian lithosphere, J. Geophys. Res. 108 (2003), doi:10.1029/ 2003JE002049.

[36] D.J. Dunlop, G. Kletetschka, Multidomain hematite: a source of planetary magnetic anomalies?, Geophys. Res. Lett. 28 (2001) $3345-3348$.

[37] P. Rochette, V. Sautter, F. Brunet, V. Chevrier, J.P. Lorand, Matching Martian magnetic anomalies and SNC magnetic properties, Lunar Planet. Sci. 33 (2002) 1199 (CD-ROM).

[38] G. Kletetschka, N.F. Ness, P.J. Wasilewski, J.E.P. Connerney, M.H. Acuña, Possible mineral sources of magnetic anomalies on Mars, Leading Edge 22 (2003) 766-768.

[39] F. Nimmo, M.S. Gilmore, Constraints on the depth of magnetized crust on Mars from impact craters, J. Geophys. Res. 106 (2001) 12,315-12,323.

[40] C.V. Voorhies, T.J. Sabaka, M. Purucker, Localized gravity/ topography admittance and correlation spectra on Mars: implications for regional and global evolution, J. Geophys. Res. 107 (2002), doi:10.1029/2001JE001534.

[41] J. Arkani-Hamed, Magnetization of the Martian crust, J. Geophys. Res. 107 (2002), doi:10.1029/2001JE001496.

[42] D. Smith, et al., The global topography of Mars and implications for surface evolution, Science 284 (1999) 1495-1503. 